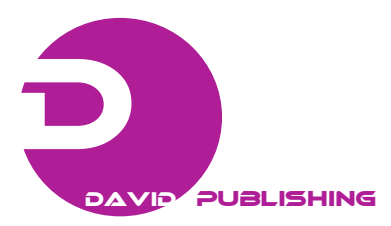

\title{
Remuneration Reforms in Public Sector: A Case of Russian Healthcare*
}

\author{
Marina Kolosnitsyna \\ National Research University Higher School of Economics, Moscow, Russia
}

\begin{abstract}
In 2008 remuneration reform for public sector was introduced in Russia. Its main idea was to implement P4P principle well-known in business, including more flexible approach to wage setting. This paper presents an attempt to estimate an influence of the new remuneration system (NRS) on earnings level, inequalities and job motivation. The estimates are based on microdata of monitoring survey of healthcare economic problems conducted in Russia in 2009 and 2010. The extended specification of Mincer earning equation and probit-models were used. One could observe increasing wage rates and earning inequalities within healthcare institutions adopted NRS though worker's experience and regional economic differences remain significant wage determining factors. As it occurs, NRS is widely adopted by large regional and central hospitals while smaller health care institutions show less enthusiasm in implementing reform. Obviously, the larger institutions have more money and better educated administrative staff to introduce the new system. Those chief physicians who adopted NRS point out a positive correlation between earnings and individual input. At the same time, those committed to old principles of wage setting more often note declining job turnover. This latter result could possibly indicate negative personnel sorting, less productive workers tending to stay with employer who doesn't assess their performance. As concerns anticipated NRS results such as increasing motivation and quality of health services, the evidence is still ambiguous.
\end{abstract}

Keywords: remuneration system, pay for performance, health care institutions, job motivation

\section{Introduction}

Health care sector in Russia has inherited many features and problems of old planned economy. First of all, one should mention its abnormal size. The numbers of physicians show an upward trend not only in relative terms but in absolute terms as well, simultaneously with depopulation in Russia (see Figure 1). The number of hospital beds though slightly reduced recently is still much higher than in other developed and transitional economies (97 beds per 10,000 of population in 2009). Yet the results of the health care system are quite modest. Russia has reduced neonatal mortality and increased average life longevity, still its position is much worse than of many other countries, not only European, but those of North Africa, South Asia and Latin America (see Figures 2-3).

\footnotetext{
* Project supported by the Basic Research Program at the National Research University Higher School of Economics (HSE). (http://www.hse.ru/en/). The author thanks E. Vladimirskaya and N. Regel for technical assistance.

Marina Kolosnitsyna, Associate Professor, Deputy head of Department for Public Economics and Public Administration, National Research University Higher School of Economics.

Correspondence concerning this article should be addressed to Marina Kolosnitsyna, \#422J, 11, Pokrovsky bul., National Research University Higher School of Economics, Moscow, 109028 Russia. E-mail: mkolosnitsyna@hse.ru.
} 


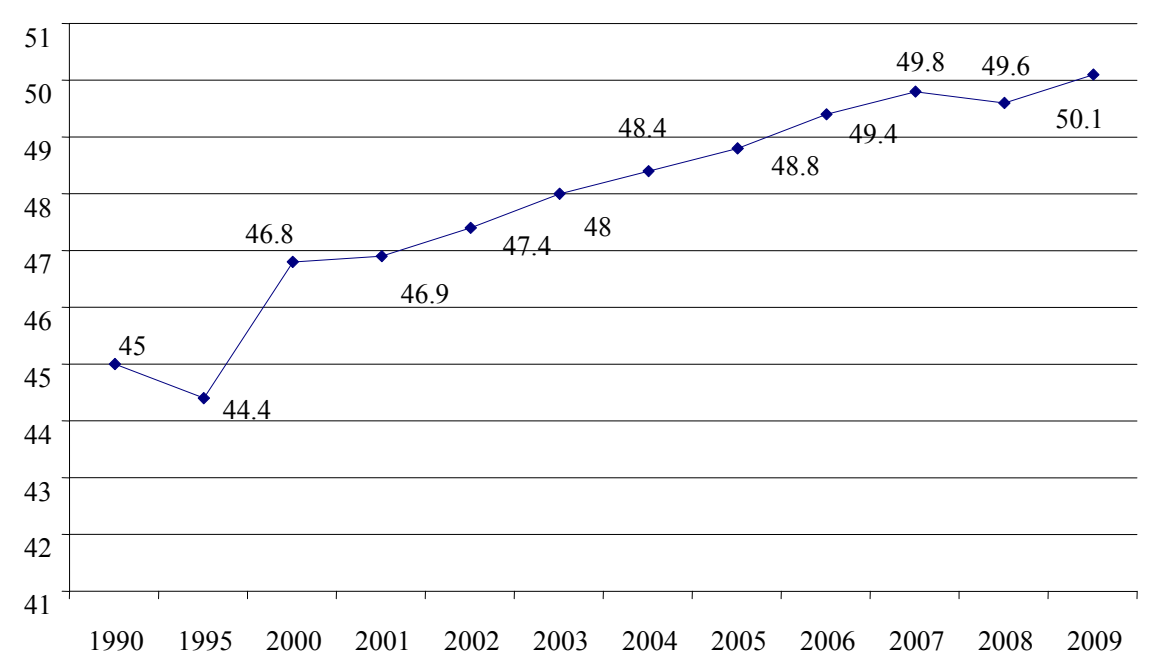

Figure 1. Physicians density per 10,000 population, 1990-2009. Source. Russian Statistical Agency.
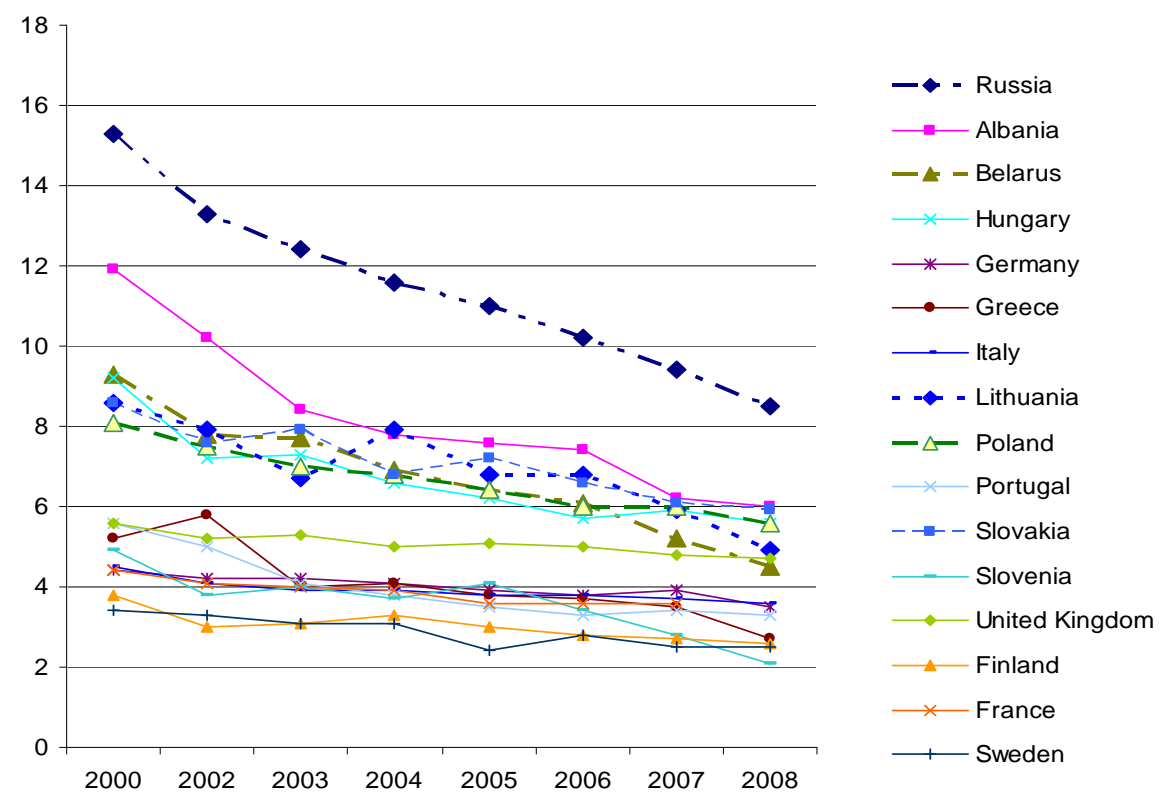

Figure 2. Neonatal mortality-Deaths/1,000 live births, 2000-2008. Source: OECD Health Data, Russian Statistical Agency.

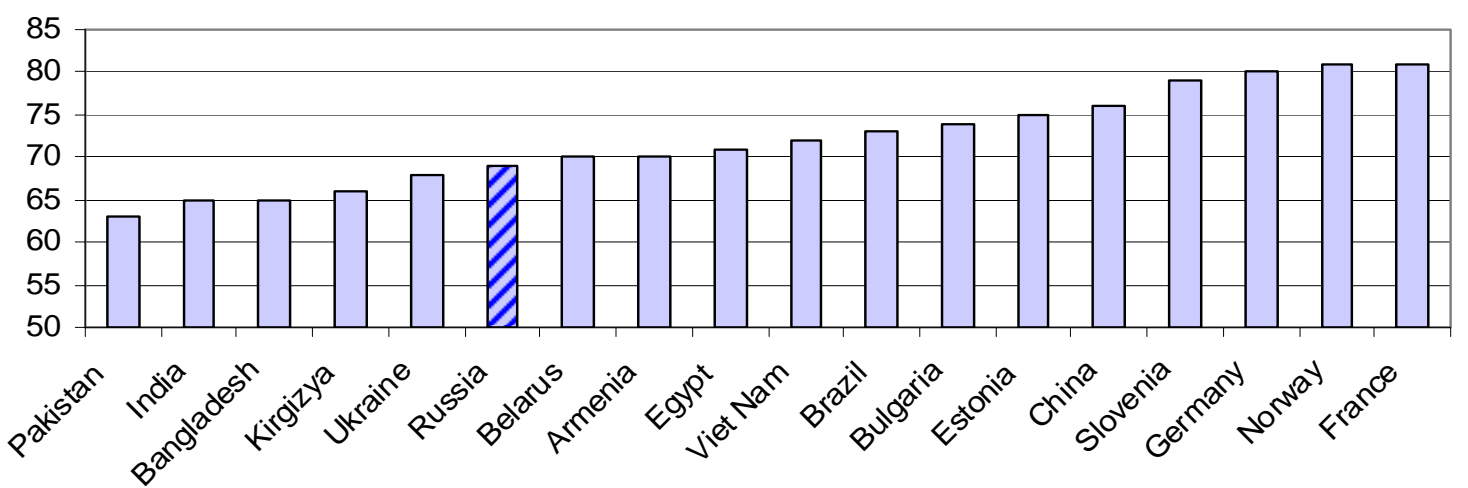

Figure 3. Life expectancy at birth, 2007-2009. Source: WHO, Global Health Observatory Data Repository; Russian Statistical Agency. 
Thus public health expansion that could be measured as a share of medical workers among employed (about $7 \%$ ) does not correspond to the ultimate results of health care system. It poses the eternal question on public sector low productivity known in literature as "Baumol disease". W. Baumol (1967) pointed out the relatively labor-intensive activity and slow productivity rise in public sector compared to the private one. Labor-intensive production type, in its turn, predetermines relatively low earnings.

It's often mentioned that Russian doctors and nurses get very low wages. That fact is being widely used to explain the lack of system's effectiveness. Indeed, the relative monthly wage of health care worker was at $60 \%$ level of average wage in economy in 2000 and amounted to $76 \%$ in 2006. On the other hand, Russian health care personnel work less than average worker in economy. Historically and legally, in medicine the official normal working hours are 35 per week compared to 40 hours per week for great majority of other employees. Real working hours (including overtime and part-time additional job) are about 41 per week for medical workers and 44 for all other workers ${ }^{1}$. Thus relatively low monthly wages in health care are compensated, at least partially, by reduced working hours. In 2006-2007 Russian government introduced a set of National Priority Projects, "Health Care" one of them. Among other measures, salaries of all primary care workers in outpatient clinics were proportionally increased. Still, in 2010 an average medical worker earned $80 \%$ and an average doctor-about $99 \%$ of mean wage in economy. The question is, whether healthcare personnel perceive recent wage raise as a stimulus for better work, or not. It seems that the new wage level is still insufficient compared to increasing earnings of other professionals, especially in private sector. Insufficient pay raise, in its turn, doesn't change personnel's work attitudes (Mitra, Gupta, \& Jenkins, 1997).

The problem of wage setting at the efficient level has been studied in economic literature for decades. In their seminal papers Solow, Akerlof, and Yellen, Shapiro, and Stiglitz show that efficiency wage enhances worker's motivation, reduces shirking and labor turnover thus giving employer additional gains (Solow, 1979; Akerlof \& Yellen, 1986; Shapiro \& Stiglitz, 1984). Salop (1979) points out lower costs of labor turnover associated with higher wages. Katz (1986) notes also positive personnel selection as a result of efficiency wage setting. Theoretical models however fail to predict the precise level of efficient wage for a particular firm or branch of economy.

More of it, a wage level itself is not the only factor motivating (or de-motivating) a worker. It's well known from theory of personnel economics and numerous empirical studies that a payment system and a type of employee's contract might be more influential than salary raise (Lazear, 1995). Performance-related or result-oriented pay often help to solve a problem of personnel motivation. Certainly it's not that easy to measure a performance or results of physicians' work. As Maynard (2006, pp. 145-146) pointed out, "the focus remains on indicators of failure rather than success in improving the health status of patients. The routine measurement of success, or improvements in the functional status of patients, remains unusual". Moreover, serious problems could appear in organization due to increasing pay differences among employees. According to special research in organizational behavior, greater earning dispersion enhances performance of most productive and well-paid workers while those less paid become even less productive, feeling deprived (Bloom, 1999; Cowherd \& Levine, 1992; Shaw, 2002). Lazer explains that result-oriented pay works well for young and non-experienced employees whereas for elder workers with high level of specific human capital it's not necessary as they usually don't have

\footnotetext{
${ }^{1}$ Author's estimates based on the data of Russian Longitudinal Monitoring Survey (Retrieved from http://www.hse.ru/rlms/spss).
} 
better alternatives "outside" the firm. Yet regardless numerous "pros" and "contras" performance-related pay is a part of the key policy options and new approaches to human resources management in the public sector around the world (OECD, 2005).

In 2008 remuneration reform for public sector was introduced in Russia. Its main idea was to implement P4P principle, including more flexible approach to wage setting. Since the very beginning of market reforms in 1992 all the public sector workers got their wages according to unified tariff system (UTS). This system sets very strict rules and boundaries for maximum and minimum wage level depending on worker's position and qualification. In fact, there was no much differences between young and more experienced workers, more or less qualified personnel. The UTS system didn't give a chief physician much room to stimulate best doctor or nurse. For many years it has been criticized for its rigidity and lack of stimuli.

Now there are only limits for minimum wage, not for maximum. At least $30 \%$ of total earnings are not guaranteed but depends on worker's performance. In theory, performance-based compensation should increase employees' productivity thus giving a possibility to decrease their excessive numbers. According to the new rules, chief physician could reduce staff keeping the same wage bill, subject to constant amount of hospital services. It gives a possibility to redistribute money to more productive workers and achieve higher level of motivation. At the same time, a number of healthcare institutions implementing new remuneration system (NRS) got additional financial support from federal or regional budget that augmented their wage funds by $30 \%$. Thus they could preserve the same stuff and increase wages for everybody. New system has been adopted by various public sector units during 2008-2010. Up to the moment, the results of reform are unclear.

The paper presents an attempt to estimate effects of new remuneration system in Russian public health institutions. First and second sections give data description and descriptive statistics. Then main hypotheses and research methodology are discussed, following by regression analysis results, discussion and conclusions.

\section{Data Description}

To estimate the impact of remuneration reform we use the data of Healthcare Problems Monitoring conducted in Russia in 2009 and $2010^{2}$. The first wave of survey in 2009 was based on a questionnaire for doctors and nurses of public health institutions in three Russian regions (oblast). One of them is relatively rich, the second one has average income and the third one is the poorest. The survey included four representative types of health care institutions: main hospitals of the regions (oblast hospitals); central regional hospitals; city hospitals and outpatient clinics (polyclinics). The total number of health institutions was 46 . Thirty four of them have already implemented the NRS, 12 have not. One thousand five hundred and ninety eight doctors and nurses were asked about their wages, bonuses, working hours, job attitudes etc.. The chief physicians of health institutions were already interviewed.

The second wave of survey conducted in 2010 includes only the information given by chief physicians of 1,027 various hospitals and poly clinics of 40 Russian regions. The same four types of healthcare institutions were included in the sample. Head doctors answered a number of questions concerning remuneration reform, its results and obstacles. Of those institutions 552 or $54 \%$ have implemented NRS, $46 \%$ still preserved the old

\footnotetext{
${ }^{2}$ The monitoring survey was conducted for Higher School of Economics by Russian Statistical Agency (Retrieved from http://www.gks.ru ) in 2009 and by Levada-Centre (Retrieved from http://www.levada.ru/) in 2010.
} 
principles of wage setting.

Thus, the information from the first wave of monitoring gives us a possibility to estimate pecuniary results of NRS as we have data on personnel wages on micro-level. The second wave gives no such data. However, in 2010 the sample of regions is wide (almost a half of Russian regions). So this data can be used to reveal the obstacles for reforms, the factors influencing NRS implementation. We could also estimate indirectly the NRS impact on wages, job motivation, workers turnover and quality of services using the chief physicians' answers.

\section{Descriptive Statistics}

Data of year 2009 reveals a high degree of information asymmetry concerning NRS introduction. There were 46 healthcare institutions in the survey sample, 34 of them have already adopted the new wage setting system by the moment of survey. One thousand five hundred and ninety eight doctors and nurses were asked if their clinic has changed the payments system. Fifty two percent of respondents gave positive answer, 19\% said "No", 29\% were undecided. In fact according to chief physicians answers 1,105 medical workers, or $71.2 \%$ of all respondents, got their wages under the new remuneration system. Therefore, only $70 \%$ of personnel in the institutions adopted NRS were informed about the fact of reform. It seems that such a lack of information couldn't contribute to reform's success. If the workers know nothing about the new system as such they could hardly become more motivated by performance-based wage.

Data of year 2010 shows that the process of NRS implementation was more or less intensive in various Russian regions. Among 40 regions in our sample 10 has fully completed the transition from the old system of wage setting to the new one. On the contrary, there were four regions, where no institution has changed remuneration principles till the moment of survey in 2010. In other 26 regions the process was not completed, some of the institutions have changed the system, others have not. One should note that the healthcare institutions of different types were more or less keen on implementing NRS. It seems that the share of institutions adopted NRS by the moment of survey is much higher among main hospitals of the regions (oblast hospitals) and central regional hospitals (see Table 1). Among the smaller institutions such as city hospitals and poly clinics this share is lower that could be explained by their worse financial position and lack of professional management. Obviously, the larger institutions have more money and better educated administrative staff to implement reform.

Table 1

Number and Share of Health Care Institutions Implemented New Remuneration System by July 2010, by Types of Institutions

\begin{tabular}{|c|c|c|c|c|c|c|}
\hline \multirow{2}{*}{\multicolumn{2}{|c|}{ Types of health institutions }} & \multirow{2}{*}{$\begin{array}{l}\text { Total number } \\
\text { of institutions }\end{array}$} & \multicolumn{2}{|c|}{ New remuneration system } & \multicolumn{2}{|c|}{ Old system of wage setting } \\
\hline & & & Number & $\%$ & Number & $\%$ \\
\hline 1 & Main hospitals of the regions (oblast hospitals) & 41 & 32 & 78 & 9 & 22 \\
\hline 2 & Central regional hospitals & 248 & 164 & 66 & 84 & 34 \\
\hline 3 & City hospitals & 355 & 162 & 46 & 193 & 54 \\
\hline \multirow[t]{2}{*}{4} & Outpatient clinics (polyclinics) & 383 & 194 & 51 & 189 & 49 \\
\hline & Total & 1,027 & 552 & & 475 & \\
\hline
\end{tabular}

Among the obstacles to the new system head physicians name lack of money ( $65 \%$ of respondents) and need for more specific instructions for wage setting ( $47 \%$ of respondents). Those chief physicians who adopted NRS point out increasing average wage and earning differences, they note also positive correlation of earnings and 
individual input more often than those who stick to old remuneration system (see Table 2).

Table 2

Transformation of Employment and Earnings Characteristics, Mentioned by Chief Physicians, \% (A respondent could choose several answers) ${ }^{*}$

\begin{tabular}{llll}
\hline & & $\begin{array}{l}\text { Among institutions } \\
\text { implemented NRS (\%) }\end{array}$ & $\begin{array}{l}\text { Among institutions preserving } \\
\text { the old payment system (\%) }\end{array}$ \\
\hline 1 & Average wage level raising & 54 & 33 \\
2 & Earning differences raising & 29 & 21 \\
3 & A share of earning that is not guaranteed rising & 28 & 23 \\
4 & Earning dependency on individual input increasing & 38 & 34 \\
5 & Stuff reducing & 14 & 14 \\
6 & Job turnover decreasing & 11 & 21 \\
7 & Discipline and motivation increasing & 28 & 32 \\
\hline
\end{tabular}

Note. ${ }^{*}$ all the differences are statistically significant.

At the same time, those committed to old principles of wage setting note declining job turnover more often. This latter result could possibly indicate negative personnel sorting, less productive workers tending to stay with employer who doesn't assess their performance. It's also important to note that staff reductions were not popular in healthcare institutions, regardless the remuneration system. This result can be explained by rigid labor legislation. It's not that easy to fire a permanent worker in Russia, and the great majority of healthcare employees in public institutions have permanent job contracts.

As concerns anticipated NRS results such as increasing motivation and quality of health services, the evidence is ambiguous. On the one hand, head doctors of hospitals that implemented new system do not mention increasing job motivation more often comparing to those who didn't change remuneration principles. In both groups $55 \%$ of chief doctors say that work attitude of their personnel hadn't changed. On the other hand, in the group of hospitals implemented NRS the reported number of physicians' faults revealed by insurance companies and Health Ministry decreased significantly comparing to the group of medical institutions preserving old wage system.

\section{Main Hypotheses and Research Methodology}

Taking into account the main features of the old and new remuneration systems (see Table 3) one could expect that performance-based and more flexible system of pay might change characteristics of earnings and stuff motivation.

Namely, three hypotheses were tested using regression analysis and the data of both waves of the Healthcare Problems Monitoring:

$\mathrm{H} 1$ : raising average wage.

H2: extended earnings inequality.

H3: enhanced workers' motivation.

At the first step the extended specification of Mincer earning equation is estimated. The equation gives a possibility to reveal the impact of different exogenous factors on worker's earnings, other things equal. Initially Jacob Mincer introduced it to show the influence of education, later on he and his followers included a number of other variables controlling for experience, qualification, gender, family status, region and other characteristics 
explaining the wage differences (Mincer, 1958, 1975). We use the same model including the type of remuneration system in the hospital/polyclinic, where the respondent works. The data of the first wave of the Monitoring (2009) gives information on individual characteristics of 1,598 health care workers. The extended Mincer equation that was estimated took following form:

$$
\begin{aligned}
& \ln W=a_{0}+a_{1} \text { AGE }+a_{2} \text { EXP }+a_{3} \text { EXP }^{2}+a_{4} \text { TEN }+a_{5} \text { TEN }^{2}+ \\
& a_{6} \text { SEX }+a_{7} \text { FAMILY }+a_{8} \text { CHILD }+a_{9} \text { QUALIF } \\
& +a_{10} \text { REG }+a_{11} \text { PAYSYSTEM }+\varepsilon_{i}
\end{aligned}
$$

Where: $\ln W$ - logarithm of average wage during previous three months;

AGE-age;

$E X P$ - working experience in health care (years);

$T E N$-working experience in this particular institution (years);

$S E X$ —sex (dummy): 0 - male, 1 -female;

FAMILY - marital status (dummy): 1 -married, 0 - single;

CHILD — number of children;

QUALIF-qualification (dummy): 0-no qualification, 1-second qualification group, 2-first qualification group, 3 - higher qualification group;

$R E G$ - region (dummy): 0 - region C (poor), 1—region B (average), 2-region A (rich);

PAYSYSTEM - remuneration system (dummy): 1 -NRS, 0 - no NRS.

Table 3

Evolution of Wage-Setting Systems in Russian Public Sector

\begin{tabular}{|l|l|l|}
\hline & \multicolumn{1}{|c|}{ Unified tariff system (UTS) 1992-2008 } & \multicolumn{1}{|c|}{ New remuneration system (NRS) 2008- } \\
\hline Wage level & $\begin{array}{l}\text { Depends on worker's position and formal } \\
\text { qualification; minimum and maximum are set } \\
\text { for every position }\end{array}$ & $\begin{array}{l}\text { Depends on worker's position, qualification, } \\
\text { performance; minimum is set, maximum is not } \\
\text { set }\end{array}$ \\
\hline Wages fund & $\begin{array}{l}\text { Depends on the amount of services and stuff } \\
\text { number }\end{array}$ & $\begin{array}{l}\text { Depends on the amount of services; doesn't } \\
\text { depend on stuff number; augmented by 30\% }\end{array}$ \\
\hline Average wage level & Low & Higher (?) \\
\hline $\begin{array}{l}\text { Earning inequality within and } \\
\text { between the qualification groups }\end{array}$ & Low & Higher (?) \\
\hline Motivation level & Low & Higher (?) \\
\hline
\end{tabular}

Taking into account the obvious difference between two main types of health care workers-doctors and nurses - at the second step two separate equations were estimated for the named groups. Excluding step by step insignificant variables and those mutually correlated we get two reduced versions of extended Mincer equation leading to some conclusions with regard to NRS influence. The reduced versions have the same form both for physicians and for nurses though the coefficients are different (see Tables 4 and 5):

$$
\ln W=a_{0}+a_{1} E X P+a_{2} E X P^{2}+a_{3} R E G+a_{4} \text { PAYSYSTEM }+\varepsilon_{i}
$$

At the third step of analysis the data of second wave of the monitoring was used, i.e., the chief physicians' questionnaires (2010). Among others, they answered two direct questions: "Did you observe the increasing discipline and job motivation of your personnel during the previous year?" and "Had the average monthly wage grown up during the year?" Since the answers were "yes" or "no" one could use this information to construct binary (probit) models to estimate the factors determining the probability of wage growth and enhancing 
workers' motivation. First of all, among possible explanatory variables are the characteristics of payment system (NRS implementation, wage dependence on worker's personal input, job quality, worker's qualification). Taking into account the survey's descriptive statistics one could also assume that the type of institution and the regional financial wealth might be influential predictors for medical personnel wage level and commitment to their job.

Two reduced versions of binary models for "wage growth" and "enhanced motivation" were obtained excluding step by step insignificant variables:

$$
\begin{aligned}
& P(\text { WAGE }=1)=a_{0}+a_{1} \text { INPUT }+a_{2} \text { QUALITY }+a_{3} \text { QUALIFY }+ \\
& +a_{4} \text { WAGEREG }+a_{5} \text { NRS }+\varepsilon_{i} \\
& P(\text { MOTIV }=1)=a_{0}+a_{1} N R S+a_{2} \text { TYPE }+a_{3} \text { WAGEREG }+\varepsilon_{i}
\end{aligned}
$$

Where: $W A G E$-dummy-variable, $=1$, if the average wage has grown up; $=0$, if no;

MOTIV - dummy-variable, $=1$, if the discipline and motivation of personnel increased in the institution; $=0$, if no;

INPUT — dummy-variable, $=1$, if the wage level depends on worker's individual input;

QUALITY — dummy-variable, $=1$, if the wage level depends on job quality;

QUALIFY - dummy-variable, = 1, if the wage level depends on worker's qualification;

WAGEREG - average monthly wage of health care workers in the region in year 2009;

TYPE—-type of institution (dummy), 1-main hospitals of the regions (oblast hospitals);

2-central regional hospitals; 3 - city hospitals; 4 -outpatient clinics (polyclinics);

NRS - dummy-variable, $=1$, if NRS was adopted in the institution; $=0$, if no.

Since the models (3)-(4) are binary, marginal effects were calculated to make an interpretation of coefficients (see Tables 6 and 7).

\section{Regression Analysis Results}

Regression (2) was estimated separately on individual data for two groups of medical personnel - physicians and nurses. In both cases, the influence of NRS on wage level was positive, as predicted. On average, the new remuneration system adds $34 \%$ to doctor's wage and $16 \%$ to nurse's wage, other things equal, so vertical earning dispersion grows. Job experience is of higher importance for physicians than for nurses, its impact more evident in the beginning of working carrier ( $a_{1}$ is positive, $a_{2}$ is negative). For both groups of workers regional factor is significant, wealthy the region higher the earnings of medical personnel (see Tables 4 and 5). Therefore individual data confirms hypotheses $\mathrm{H} 1$ and $\mathrm{H} 2$ - wage level rising as well as wage inequality in the healthcare institutions adopted NRS.

Table 4

Estimation Results for Mincer Equation, Physicians

\begin{tabular}{lcl}
\hline Ln $W$ & & \\
\hline Variables & Coefficients & Std. error \\
\hline EXP & $0.03387^{* * *}$ & 0.00385 \\
EXP2 & $-0.00072^{* * *}$ & 0.00008 \\
REG & $0.13504^{* * *}$ & 0.01598 \\
PAYSYSTEM & $0.34097^{* * *}$ & 0.05387 \\
\hline
\end{tabular}

Notes. ${ }^{* * * *}$ means $p<0.01 ; R^{2}=0.111 ; F$-statistic $=43.44 ;$ Number of observations $=765$. 
Table 5

Estimation Results for Mincer Equation, Nurses

\begin{tabular}{lcl}
\hline Ln $W$ & & \\
\hline Variables & Coefficients & Std. error \\
\hline EXP & $0.01466^{* * *}$ & 0.00397 \\
EXP2 & $-0.00033^{* * *}$ & 0.00008 \\
REG & $0.11090^{* * *}$ & 0.01672 \\
PAYSYSTEM & $0.16286^{* * *}$ & 0.05630 \\
\hline
\end{tabular}

Notes. $^{{ }^{* * * *}}$ means $p<0.01 ; R^{2}=0,094 ; F$-statistic $=19.29 ;$ Number of observations $=749$.

Estimates based on probit-model (3) also show positive and significant correlation between NRS implementation in health care institution and wage growth (see Table 6). Probability of wage growth is $14 \%$ higher in hospitals that adopted the new system. Wage dependence on individual input and quality of work adds $11.7 \%$ and $9.4 \%$ to probability of earning growth. On the contrary, wage dependence on worker's qualification tends to decrease probability of wage rising. It's interesting to note that higher average wage of medical workers in the region in previous year reduces the probability of wage growth in 2010 (though the coefficient before WAGEREG is very small). Obviously, in those relatively wealthy regions the wage level in health care is already quite high so the further growth becomes modest regardless the remuneration reform. Again, the probit-model confirms the hypothesis H1, positive correlation established between NRS adoption and wage rising.

Table 6

Probit-Model for Wage Growth, Marginal Effects

\begin{tabular}{lll}
\hline \multirow{2}{*}{ Variables } & \multicolumn{2}{c}{ Wage growth $P($ WAGE $)=1$} \\
\cline { 2 - 3 } & Coefficients (marginal effects) & Std. error \\
\hline INPUT & $0.1167^{* *}$ & 0.0463 \\
QUALITY & $0.0945^{*}$ & 0.0514 \\
QUALIFY & $-0.1908^{*}$ & 0.0976 \\
WAGEREG & $-0.00001^{* * *}$ & 0.0000 \\
NRS & $0.1411^{* * *}$ & 0.0331 \\
\hline Notes. ${ }^{* * * *}$ means $p<0.01,{ }^{* *}$ means $p<0.05,{ }^{*}$ means $p<0.1 ; R^{2}=0.054 ; F$-statistic $=75.89 ;$ Number of observations $=1,026$.
\end{tabular}

Table 7

Probit-Model for Discipline and Motivation Enhancing, Marginal Effects

\begin{tabular}{lcc}
\hline \multirow{2}{*}{ Variables } & \multicolumn{2}{c}{ Discipline and motivation enhancing $P(M O T I V)=1$} \\
\cline { 2 - 3 } & Coefficients (marginal effects) & Std. error \\
\hline TYPE & $0.0463^{* * *}$ & 0.0137 \\
WAGEREG & $0.0111^{* * *}$ & 0.0000 \\
NRS & $-0.0711^{* * *}$ & 0.0243 \\
\hline Notes. ${ }^{* * *}$ means $p<0.01 ; R^{2}=0.059 ; F$-statistic $=52.71 ;$ Number of observations $=1,026$.
\end{tabular}

As concerns the probability of enhanced discipline and motivation (probit-model (4)), the type of institution was found significant. Higher the status of clinic higher the probability of rising motivation, other things equal. Every step (from poly clinic to city hospital, from city hospital to central regional hospital, etc.) adds $4.6 \%$ to probability of enhanced motivation. Similar influence has a factor of regional average wage in health care. Higher the wages, better the discipline and motivation. What looks curious, that's negative correlation between NRS 
adoption and rising motivation. The probability of motivation growth is $7.1 \%$ lower for clinics implemented new wage setting system (see Table 7). Thus the hypothesis H3 must be rejected.

\section{Discussion and Conclusions}

Healthcare institutions adopted the new remuneration system are characterized by increasing wage rates and higher earning inequalities. Physicians get higher wage premiums from NRS comparing to nurses so wage dispersion rises. At the same time, worker's experience and regional economic differences remain significant wage determining factors. In those institutions where wage level depends on workers' individual input and quality of work one observes higher probability of wage growth. On the other hand, the factor of qualification doesn't increase worker's wage. That fact might indicate that formal qualification characteristics in health care sector don't play a signal role any more. As concerns anticipated NRS results such as rising motivation and quality of health services, the evidence is still ambiguous. Negative NRS impact on probability of motivation growth could be a signal of workers' antagonism against the reform. At the same time, it could be just a sequence of ignorance. One shouldn't forget that pecuniary results of a new wage setting system appear immediately while the developments of workers' job attitudes usually take much more time.

\section{References}

Akerlof, G. A., \& Yellen, J. L. (1986). Efficiency wages models of labor market. Cambridge: Cambridge University Press.

Baumol, W. J. (1967). The macroeconomics of unbalanced growth. American Economic Review, 62(5), 777-795.

Bloom, M. (1999). The performance effect of pay dispersion on individuals and organizations. Academy of Management Journal, 42, 25-40.

Cowherd, D., \& Levine, D. I. (1992). Product quality and pay equity between low-level employees and top management: an investigation of distributive justice theory. Administrative Science Quarterly, 37(2), June, 302-320;

Katz, L. F. (1986). Efficiency wage theories: A partial evaluation. NBER working papers, 1906. National Bureau of Economic Research.

Lazear, E. D. (1995). Personnel economics. Cambridge, London: The MIT Press.

Maynard, A. (2006). Incentives in health care: The shift in emphasis from the implicit to the explicit. In C. A. Dubois, M. McKee, \& E. Nolte (Eds.), Human resources for health in Europe (pp. 140-154). Open University Press, McGraw-Hill Education.

Mincer, J. (1958). Investment in human capital and personal income distribution. Journal of Political Economy, 66(4), 281-302.

Mincer, J. (1974). Schooling, experience and earnings. New York: NBER Press.

Mitra, A., Gupta, N., \& Jenkins, G. D. (1997). A drop in the bucket: When is a pay raise a pay raise? Journal of Organizational Behavior, 18, 117-137.

OECD. (2005). Performance-related pay policies for government employees. Paris: OECD.

Salop, S. (1979). A model of the natural rate of unemployment. American Economic Review, 69(March), 117-125.

Shapiro, C., \& Stiglitz, J. (1984). Equilibrium unemployment as a worker discipline device. American Economic Review, 74, 433-444.

Shaw, J. D., Gupta, N., \& Delery, J. E. (2002). Pay dispersion and work force performance: Moderating effects of incentives and interdependence. Strategic Management Journal, 23, 491-512.

Solow, R. (1979). Another possible source of wage stickness. Journal of Macroeconomics, 1, 79-82. 